\title{
RELATIONSHIP BETWEEN ANTHROPOMETRIC AND ELECTROMYO- GRAPHIC VARIABLES OF THE SCAPULAR MUSCLES
}

original paper

(1) University School of Physical Education in Wroclaw

DOI: https://doi.org/10.5114/hm.2020.88147

\section{GUILLERMO MENDEZ-REBOLLEDO ${ }^{1,2}$, EDUARDO GUZMAN-MUÑOZ ${ }^{1}$, JUAN CONCHA-ARAYA ${ }^{1}$, MATIAS ARAVENA-FALCON ${ }^{1}$, VICTOR GALVEZ-GONZALEZ ${ }^{1}$, FRANCISCO JOSE BERRAL DE LA ROSA ${ }^{2}$}

${ }^{1}$ Escuela de Kinesiología, Facultad de Salud, Universidad Santo Tomás, Chile

${ }^{2}$ Pablo de Olavide University, Seville, Spain

\begin{abstract}
Purpose. To determine the relationship between skinfolds and onset latency of scapular muscles in healthy young adults. Methods. A cross-sectional study was carried out at the Biomechanics and Motor Control Laboratory of Saint Thomas University, Talca, Chile. Overall, 36 participants between 18 and 24 years of age were selected. The axillary, pectoral, and subscapular skinfolds were measured, as well as the electromyographic onset latency of the scapular muscles (serratus anterior and trapezius) when performing a voluntary arm abduction task. The Pearson correlation coefficient was used.

Results. There was a positive correlation between the axillary skinfold and the lower trapezius $(r=0.51, p=0.002)$ and serratus anterior $(r=0.53, p=0.001)$ muscle onset latencies, and also between the subscapular skinfold and the lower trapezius $(r=0.38, p=0.022)$ and serratus anterior $(r=0.73, p<0.001)$ muscle onset latencies.

Conclusions. During a voluntary abduction arm movement, a greater thickness of axillary and subscapular skinfolds is related to an increase in the lower trapezius and serratus anterior muscle onset latencies.
\end{abstract}

Key words: nutritional status, anthropometry, surface electromyography, shoulder

\section{Introduction}

Since 1975, obesity has seen a resounding increase worldwide. In 2016, 39\% of adults presented as overweight and $13 \%$ were obese [1]. Considering these alterations is important to understand etiological factors of chronic diseases, including diabetes, cardiovascular diseases, and cancer [2]. In turn, shoulder problems were reported to be in the third place among musculoskeletal disorders and one of the main limitations in the activities of daily life [3].

The most widely used method for the classification of overweight and obesity is the body mass index (BMI), as it is easy to apply and reproduce [4]. Overweight and obesity are characterized by an accumulation of adipose tissue along the compartments of the human body, especially in the subcutaneous zone $(80 \%)$ and the central region [5]. This leads to an in- crease in chronic inflammation, producing skeletal muscle disorders that alter the kinetics, kinematics, and neuromuscular activity of the whole body $[6,7]$. In this context, the accumulation of fat has been considered as one of the factors that modify the electromyographic (EMG) record [8]. EMG allows to measure muscular electrical activity, and thus to register the electrical potential during muscular contractions through the expression of the amplitude, latency, and frequency of the EMG signal [8].

Among the methods to measure the central accumulation of fat are the waist circumference index, and subscapular (SB) and suprailiac skinfolds [9, 10]. While skinfold measurement is the most used method for determining the peripheral accumulation of fat in healthy people and athletes [9-11], it has been observed that the accumulation of subcutaneous fat generates alterations in the EMG record [8, 12], specifically

Correspondence address: Guillermo Mendez-Rebolledo, Avenida Circunvalación \#1855, Talca, Chile, Código Postal: 3460000, Universidad Santo Tomás, e-mail: guillermomendezre@santotomas.cl

Received: March 10, 2019

Accepted for publication: May 9, 2019

Citation: Mendez-Rebolledo G, Guzman-Muñoz E, Concha-Araya J, Aravena-Falcon M, Galvez-Gonzalez V, de la Rosa BFJ. Relationship between anthropometric and electromyographic variables of the scapular muscles. Hum Mov. 2020;21(1):1-6; doi: https://doi.org/10.5114/hm.2020.88147. 
a decrease of EMG amplitude [13]. Nordander et al. [13] observed a negative relationship between a greater amount of subcutaneous tissue in the arm region and EMG amplitude. On the other hand, some authors describe no relationship between skinfold measurement and muscle activity $[14,15]$. De Vito et al. [14] did not note significant results when trying to determine whether adiposity influenced the coactivation of the biceps femoralis, vastus lateralis, and rectus femoralis during an isometric extension of the knee. Despite the above, there are no reports on the relationship of the skinfolds near the scapular region and the onset latency of scapular muscles.

In this context, there are no studies that evaluate the influence of adipose tissue accumulation on the onset latency, especially of muscles that are part of the axial skeleton. The variation of latency is an important indicator of neuromuscular control, as it allows estimation of the recruitment order of the muscles that stabilize and mobilize a joint [16-18]. In this sense, it is important to understand the relationship between skinfolds and the onset latency of the scapular muscles, as if there is a relationship, this would be a determining factor when evaluating, analysing, and interpreting the surface EMG record. Thus, the purpose of this study was to determine the relationship between the skinfolds and the onset latency of the scapular muscles in healthy young adults.

\section{Material and methods}

\section{Participants}

A cross-sectional study was carried out at the Biomechanics and Motor Control Laboratory of Saint Thomas University (Chile). Participants were selected as a non-probabilistic sample of a group of students of the Faculty of Health of Saint Thomas University. A total sample of 37 subjects was calculated on the basis of an alpha risk of 0.05, power (beta risk) of 0.05 , Pearson correlation coefficient estimation of 0.6, and a dropout rate of 0.15 . The participants included were males aged 18-24 years. In the sample recruitment, the following exclusion criteria were applied: (1) incomplete shoulder range of motion; (2) history of shoulder pain; (3) participation in overhead sports; (4) observable scapular dyskinesia; (5) history of trauma, dislocation, rotator cuff tear, deformities of the spine, root symptoms, and/or neurological diseases.

\section{Instrumentation}

Body weight was assessed with scales (Seca, Hamburg, Germany; $0.1 \mathrm{~kg}$ accuracy); standing height was measured by using a stadiometer (Seca, model 220, USA; $0.1 \mathrm{~cm}$ accuracy); and pectoral (PE), axillary (AX), tricipital, SB, ileocrestal, abdominal, and anterior thigh skinfolds were determined with a Lange calliper Model C-130 (Creative Health Products, Inc., Ann Arbor, MI, USA; $0.5 \mathrm{~mm}$ precision). Surface EMG and acceleration signals were acquired with a Delsys Trigno $^{\text {TM }}$ Wireless sEMG System and recorded with the Delsys EMGworks Acquisition 4.2.0 (Delsys Inc., Boston, MA, USA). The beginning and end of the arm raise task were determined with an accelerometer (Delsys Inc. Boston, MA, USA) on the anterior deltoid surface of the dominant arm [19]. The electrodes were made of silver (99\%) and had an inter-electrode distance of $10 \mathrm{~mm}$. The sEMG was sampled at $2000 \mathrm{~Hz}$, amplified with a gain of 300, and filtered with a bandpass filter (fourth-order, Butterworth filter with frequencies between 20 and $450 \mathrm{~Hz}$ ).

\section{Procedures}

The flow chart of the study procedures can be observed in Figure 1. Body weight, height, BMI, and cutaneous skinfolds were assessed. The skinfolds were measured on the participants' right side, in accordance with a protocol described by the International Society for the Advancement of Kinanthropometry (ISAK) [20]. Two certified ISAK level II evaluators performed the measurements. Each skinfold was measured twice by an evaluator (technical measurement error: $0.91 \%$ ) and a third measurement was made by a different evaluator (technical measurement error: $0.89 \%$ ). Then, the median of the 3 repetitions performed was selected. The percentage of body fat $(\% \mathrm{BF})$ was obtained by the Siri equation, where the body density considered was the one proposed in the Jackson and Pollock equation [21], as this equation was formulated on the basis of a sample from the general population aged 18-61 years, which is the closest to the sample included in the present investigation.

Then, we proceeded to locate the electrodes on the muscles: anterior deltoid, electrode placed in the width of a distal finger and anterior to the acromion; upper trapezius, electrode placed $50 \%$ in the line from the acromion to the vertebral column in vertebra C7; middle trapezius, electrode placed $50 \%$ between the medial border of the scapula and the spine, at the level of T3; lower trapezius, electrode placed at $2 / 3$ in 


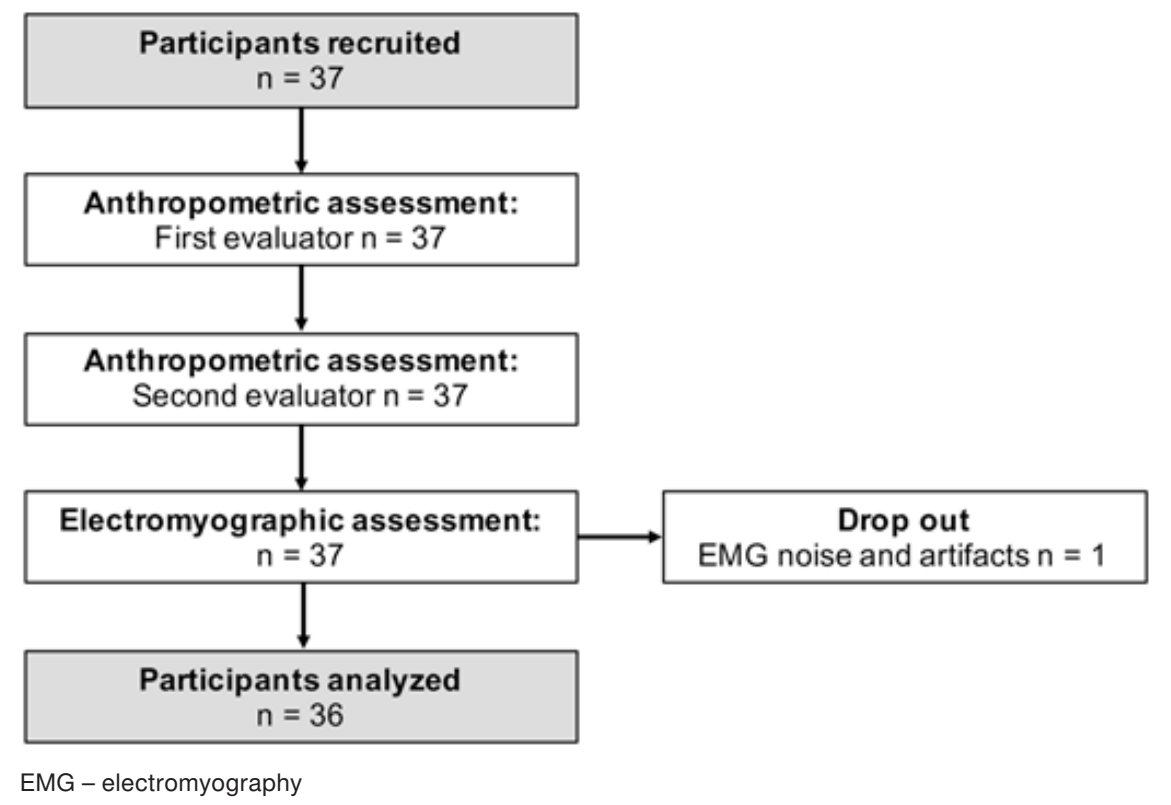

Figure 1. Flow chart of the study procedures

the line from the trigonum spinea to T8. These procedures were performed in accordance with the SENIAM recommendations [12]. In the case of the serratus anterior, the procedure was based on a previous investigation [22]. The electrodes were placed in the muscular belly in the mid-AX line of the right side on the fifth rib. Then, the participants performed stretching exercises of the glenohumeral and scapular muscles. Subsequently, they performed a voluntary arm abduction task. This consists of an elevation of the arm in the scapular plane at the rhythm of a cycle of abduction and adduction in 4 seconds, as this speed of movement is considered slow or standard [23]. Before the test, the participants were instructed to reproduce the movement speed following the rhythm established by a metrometer, and they practised the movement twice. Overall, 3 trials were performed, and each considered 3 arm elevations (abduction and adduction cycle). In each trial, the second elevation of the arm was selected; these were averaged for the subsequent analysis.

\section{Statistical analysis}

The statistical software SPSS 23.0 for Windows (SPSS Inc., Chicago) was used. The mean, standard deviation, and 95\% confidence interval of the skinfold variables and onset latency of each scapular muscle were calculated. In addition, the normal distribution was checked by using the Kolmogorov-Smirnov test. The Pearson correlation coefficient, or $r$, was used to determine the correlation between $\mathrm{BMI}, \% \mathrm{BF}$, and each skinfold (AX, PE, and SB) and the onset latency of each scapular muscle (upper trapezius, middle trapezius, lower trapezius, and serratus anterior). A Pearson correlation coefficient of $0-0.4$ was considered weak; 0.41-0.7, moderate; and 0.71-1.0, strong. The level of significance for all statistical tests was 0.05 .

\section{Ethical approval}

The research related to human use has complied with all the relevant national regulations and institutional policies, has followed the tenets of the Declaration of Helsinki, and has been approved by the Southern Centre Ethics Committee of Santo Tomás University, Chile.

\section{Informed consent}

Informed consent has been obtained from all individuals included in this study.

\section{Results}

The basic characteristics of the sample are shown in Table 1. One participant was not included in the analysis because their EMG signals presented with excessive noise and artifacts. Therefore, the following results consider 36 subjects. The Kolmogorov-Smirnov test results showed that all of the variables were normally distributed $(p<0.05)$. The Pearson correlation coefficient and significant correlations between scapular muscles and BMI, \%BF, and skinfolds are shown in Table 2. Significant relationships were observed between the AX skinfold and lower trapezius $(r=0.51$, 
G. Mendez-Rebolledo et al., Scapular anthropometry and electromyography

Table 1. Basic characteristics of the sample

\begin{tabular}{|c|c|c|c|c|c|c|c|}
\hline Characteristics & Mean & Median & $\begin{array}{l}\text { Standard } \\
\text { deviation }\end{array}$ & $\begin{array}{l}95 \% \text { confidence } \\
\text { interval }\end{array}$ & $\begin{array}{c}25^{\text {th }} \\
\text { percentile }\end{array}$ & $\begin{array}{c}50^{\text {th }} \\
\text { percentile }\end{array}$ & $\begin{array}{c}75^{\text {th }} \\
\text { percentile }\end{array}$ \\
\hline Age (years) & 22.4 & 22.0 & 1.9 & $21.7-23.0$ & 21.0 & 22.0 & 23.0 \\
\hline Height (m) & 1.74 & 1.74 & 0.05 & $1.72-1.76$ & 1.69 & 1.74 & 1.78 \\
\hline Weight (kg) & 76.6 & 76.0 & 10.5 & $73.1-80.1$ & 67.4 & 76.0 & 82.2 \\
\hline Body mass index $\left(\mathrm{kg} / \mathrm{m}^{2}\right)$ & 25.2 & 24.9 & 3.2 & $24.1-26.3$ & 23.1 & 24.9 & 26.8 \\
\hline Body fat (\%) & 18.2 & 18.7 & 3.5 & $17.1-19.4$ & 15.8 & 18.7 & 20.6 \\
\hline Axillary skinfold thickness (mm) & 16.6 & 16.3 & 3.8 & $15.3-17.9$ & 13.6 & 16.3 & 19.5 \\
\hline Pectoral skinfold thickness (mm) & 13.4 & 13.0 & 3.4 & $12.3-14.6$ & 10.7 & 13.0 & 16.0 \\
\hline Subscapular skinfold thickness (mm) & 23.0 & 23.0 & 3.6 & $21.8-24.2$ & 19.3 & 23.0 & 25.0 \\
\hline Upper trapezius onset latency (ms) & -38.4 & -45.5 & 40.5 & from -51.9 to -24.9 & -72.3 & -45.5 & -16.2 \\
\hline Middle trapezius onset latency (ms) & -27.1 & -34.7 & 76.9 & from -52.7 to -1.4 & -89.7 & -34.7 & 48.3 \\
\hline Lower trapezius onset latency (ms) & -29.0 & -13.5 & 62.5 & from -49.9 to -8.2 & -90.5 & -13.5 & 27.3 \\
\hline Serratus anterior onset latency (ms) & -16.8 & -13.5 & 72.6 & from -41.0 to 7.3 & -67.9 & -23.6 & 51.8 \\
\hline
\end{tabular}

Table 2. Correlation between skinfold thickness and scapular muscles onset latencies

\begin{tabular}{lcccccccr}
\hline & \multicolumn{2}{c}{ Upper trapezius } & \multicolumn{2}{c}{ Middle trapezius } & \multicolumn{2}{c}{ Lower trapezius } & \multicolumn{2}{c}{ Serratus anterior } \\
\cline { 2 - 8 } Parameter & $r$ & $p$ & $r$ & $p$ & $r$ & $p$ & $r$ & $p$ \\
\hline Body mass index & -0.41 & 0.070 & -0.11 & 0.509 & 0.10 & 0.548 & 0.23 & 0.170 \\
Body fat (\%) & -0.05 & 0.737 & 0.01 & 0.909 & 0.24 & 0.150 & 0.27 & 0.102 \\
Axillary skinfold & -0.13 & 0.436 & 0.29 & 0.080 & 0.51 & 0.002 & 0.53 & 0.001 \\
Pectoral skinfold & -0.12 & 0.464 & 0.11 & 0.511 & 0.22 & 0.181 & 0.27 & 0.105 \\
Subscapular skinfold & -0.17 & 0.291 & 0.29 & 0.079 & 0.38 & 0.022 & 0.73 & $<0.001$ \\
\hline
\end{tabular}

$p=0.002)$ and serratus anterior $(r=0.51, p=0.53)$ onset latency, with moderate correlation in both cases. Other significant relationships were found between the SB skinfold and lower trapezius $(r=0.38, p=0.022)$ and serratus anterior $(r=0.73, p<0.001)$ onset latency, with a strong correlation in the latter case.

\section{Discussion}

The results of this study indicate a positive and significant correlation between skinfolds and scapular muscle onset latencies during a voluntary abduction arm task. Specifically, an increase in the onset latency of the lower trapezius and serratus anterior muscles versus a greater thickness of the SB and AX skinfolds was observed. To our knowledge, there are no previous studies that relate skinfolds to the EMG latency of the scapulothoracic musculature, so this research would be the first record on the subject.

Surface EMG analysis has shown great variation among subjects even when performing exactly the same motor task [24]. It has been established that the increase of the thickness of a skinfold affects the EMG signal registration, contaminated by crosstalk, acting as a spatial filter, and decreasing its selectivity
$[8,12,13,25]$. This is reflected in the decrease in amplitude and frequency, considered the most studied EMG variables [13, 26]. The literature indicates that a higher subcutaneous fat content increases the distance between muscle and electrode, attenuating the record of the action potential [26]. The presence of this fat content not only attenuates the signal but also contaminates it by picking up signals from the neighbouring motor units [26]. Another phenomenon described is the cancellation effect, which attenuates the EMG signal through the interaction of the positive and negative phases of the action potential emitted by the motor unit, cancelling each other out and reducing the information captured by the electrode [27].

On the other hand, some authors mention that there is no relationship between skinfold thickness and muscle activity $[14,15]$. They did not observe significant results when trying to determine whether adiposity influenced coactivation of the femoral biceps, vastus lateralis, and rectus femoris during the isometric extension of the knee. On the other hand, previous studies have suggested that a higher BMI decreases resistance to fatigue $[28,29]$ and affects the development of motor tasks [30]. This is because the greater fat content around the muscle has a close relationship with the 
infiltration of fat in the muscle fibres [5], which favours inflammation and impairs muscular mechanical efficiency [31, 32]. In turn, fatigue affects motor control and the order of recruitment of the scapular muscles during an arm raise task [17]. Therefore, it is important to know the muscle performance prior to the EMG evaluation, since fatigue affects the onset latency and muscle recruitment order. Despite the above evidence, none of these authors specifically refers to the influence of the skinfolds on the onset latency of the scapular muscles.

It is known that the recruitment order of the scapular muscles varies depending on the characteristics of the motor task. For example, during an arm raise, a specific scapular recruitment order is observed [19]. There is an activation pattern from proximal to distal, involving the scapular and spinal stabilizers (serratus anterior and lower trapezius) before the arm mobilizers (anterior deltoid) and the rotator cuff during an arm movement [19, 24, 33]. In this context, our findings indicate that a greater skinfold will cause a delay in the onset latency of the scapular muscles, and therefore an alteration of motor control and performance during an arm raise task. These results should be considered during procedures of acquiring and processing EMG signals in sports science. In addition, fitness professionals should respect the effect of subcutaneous and intramuscular fat of the scapular and shoulder muscles, which can influence muscle metabolic performance in laboratory and field tests.

Within the limitations of this study, the recruitment of only men and the convenience selection criteria of the participants could increase the type I error of the investigation. On the other hand, the measurement of skinfolds is a dependent measurement of the evaluator and expresses an estimate of the subcutaneous fat content and, indirectly, the intramuscular fat. Therefore, it would be useful to carry out future investigations that would relate the skinfolds, the muscular cross-sectional area, and the muscular fat infiltration by means of magnetic resonance imaging and the EMG record.

\section{Conclusions}

During a voluntary abduction arm movement, the presence of a greater $\mathrm{AX}$ and $\mathrm{SB}$ skinfold is related to an increase in lower trapezius and serratus anterior onset latencies. The increase in onset latency may be a consequence of a combination of physical factors (EMG signal attenuation) and metabolic factors (muscle fat infiltration). In this context, the study contributes to the understanding that a greater skinfold influences the objectivity and clinical reliability of the EMG latency registry, this being important for a correct diagnostic approach that leads to optimal rehabilitation. In accordance with the results of this study and previous reports, we asked if there was an optimal percentage of subcutaneous adiposity for a reliable EMG record.

\section{Acknowledgments}

This work was supported by the Vice-Rector for research and postgraduate studies at Saint Thomas University (Chile); Internal Research Project ID-106.

\section{Disclosure statement}

No author has any financial interest or received any financial benefit from this research.

\section{Conflict of interest}

The authors state no conflict of interest.

\section{References}

1. World Health Organization. Obesity and overweight. 2018. Available from: http:/www.who.int/news-room/ fact-sheets/detail/obesity-and-overweight.

2. Egger G, Dixon J. Beyond obesity and lifestyle: a review of 21 st century chronic disease determinants. Biomed ResInt. 2014;2014:731685; doi:10.1155/2014/731685.

3. Saldiran TC, Yilmaz O. Which one is the most limited movement in restricted shoulder joint. Hum Mov. 2019;20(2):72-78; doi: 10.5114/hm.2019.83220.

4. Javed A, Jumean M, Murad MH, Okorodudu D, Kumar S, Somers VK, et al. Diagnostic performance of body mass index to identify obesity as defined by body adiposity in children and adolescents: a systematic review and meta-analysis. PediatrObes. 2015;10(3):234244; doi: 10.1111/ijpo.242.

5. Clarys JP, Provyn S, Marfell-Jones MJ. Cadaver studies and their impact on the understanding of human adiposity. Ergonomics. 2005;48(11-14):1445-1461; doi: 10.1080/00140130500101486.

6. Garcia-Vicencio S, Martin V, Kluka V, Cardenoux C, Jegu AG, Fourot AV, et al. Obesity-related differences in neuromuscular fatigue in adolescent girls. Eur J Appl Physiol. 2015;115(11):2421-2432; doi: 10.1007/ s00421-015-3222-9.

7. Lee D, Shook RP, Drenowatz C, Blair SN. Physical activity and sarcopenic obesity: definition, assessment, prevalence and mechanism. Future Sci OA. 2016;2(3): FSO127; doi: 10.4155/fsoa-2016-0028.

8. Vigotsky AD, Halperin I, Lehman GJ, Trajano GS, Vieira TM. Interpreting signal amplitudes in surface electromyography studies in sport and rehabilitation sciences. Front Physiol. 2018;8:985; doi: 10.3389/ fphys.2017.00985. 
9. Madden AM, Smith S. Body composition and morphological assessment of nutritional status in adults: a review of anthropometric variables. J Hum Nutr Diet. 2016;29(1):7-25; doi: 10.1111/jhn.12278.

10. Domínguez-Reyes T, Quiroz-Vargas I, Salgado-Bernabé AB, Salgado-Goytia L, Muñoz-Valle JF, ParraRojas I. Anthropometric measurements as predictive indicators of metabolic risk in a Mexican population [in Spanish]. Nutr Hosp. 2017;34(1):96-101; doi: 10.20960/nh.983.

11. Kirk C. Does anthropometry influence technical factors in competitive mixed martial arts? Hum Mov. 2018; 19(2):46-59; doi: 10.5114/hm.2018.74059.

12. Hermens HJ, Freriks B, Disselhorst-Klug C, Rau G. Development of recommendations for SEMG sensors and sensor placement procedures. J Electromyogr Kinesiol. 2000;10(5):361-374; doi: 10.1016/S10506411(00)00027-4.

13. Nordander C, Willner J, Hansson GA, Larsson B, Unge J, Granquist L, et al. Influence of the subcutaneous fat layer, as measured by ultrasound, skinfold calipers and BMI, on the EMG amplitude. Eur J Appl Physiol. 2003;89(6):514-519; doi: 10.1007/s00421003-0819-1.

14. De Vito G, McHugh D, Macaluso A, Riches PE. Is the coactivation of biceps femoris during isometric knee extension affected by adiposity in healthy young humans? J Electromyogr Kinesiol. 2003;13(5):425-431; doi: 10.1016/S1050-6411(03)00061-0.

15. Stock MS, Thompson BJ. Adipose tissue thickness does not affect the electromechanical delay. Physiol Meas. 2016;37(3):418-428; doi: 10.1088/0967-3334/37/3/418.

16. Cools AM, Witvrouw EE, De Clercq GA, Danneels LA, Willems TM, Cambier DC, et al. Scapular muscle recruitment pattern: electromyographic response of the trapezius muscle to sudden shoulder movement before and after a fatiguing exercise. J Orthop Sport Phys Ther. 2002;32(5):221-229; doi: 10.2519/jospt.2002.32.5.221.

17. Mendez-Rebolledo G, Gatica-Rojas V, Guzman-Muñoz E, Martinez-Valdes E, Guzman-Venegas R, Berral de la Rosa FJ. Influence of fatigue and velocity on the latency and recruitment order of scapular muscles. Phys Ther Sport. 2018;32:80-86; doi: 10.1016/j.ptsp.2018. 04.015 .

18. Santos MJ, Soldado GCD, Marconi NF, Gil AL. Muscular activation patterns in swimmers with asymptomatic shoulder joint instability. Hum Mov. 2013;14(1): 56-63; doi: 10.2478/humo-2013-0004.

19. Mendez-Rebolledo G, Gatica-Rojas V, Martinez-Valdes E, Xie HB. The recruitment order of scapular muscles depends on the characteristics of the postural task. J Electromyogr Kinesiol. 2016;31:40-47; doi: 10.1016/ j.jelekin.2016.09.001.

20. Marfell-Jones MJ, Stewart AD, de Ridder JH. International standards for anthropometric assessment. Underdale: International Society for the Advancement of Kinanthropometry; 2012.
21. Jackson AS, Pollock ML. Generalized equations for predicting body density of men. Br J Nutr. 1978;40(3): 497-504; doi: 10.1079/bjn19780152.

22. Lehman GJ, Gilas D, Patel U. An unstable support surface does not increase scapulothoracic stabilizing muscle activity during push up and push up plus exercises. Man Ther. 2008;13(6):500-506; doi: 10.1016/ j.math.2007.05.016.

23. Sugamoto K, Harada T, Machida A, Inui H, Miyamoto T, Takeuchi E, et al. Scapulohumeral rhythm: relationship between motion velocity and rhythm. Clin Orthop RelatRes.2002;(401):119-124; doi: 10.1097/00003086200208000-00014.

24. Seitz AL, Uhl TL. Reliability and minimal detectable change in scapulothoracic neuromuscular activity. J Electromyogr Kinesiol. 2012;22(6):968-974; doi: 10.1016/j.jelekin.2012.05.003.

25. Farina D, Rainoldi A. Compensation of the effect of subcutaneous tissue layers on surface EMG: a simulation study. Med Eng Phys. 1999;21(6-7):487-497; doi: 10.1016/S1350-4533(99)00075-2.

26. Kuiken TA, Lowery MM, Stoykov NS. The effect of subcutaneous fat on myoelectric signal amplitude and cross-talk. Prosthet Orthot Int. 2003;27(1):48-54; doi: 10.3109/03093640309167976.

27. Minetto MA, Botter A, Šprager S, Agosti F, Patrizi A, Lanfranco F, et al. Feasibility study of detecting surface electromyograms in severely obese patients. J Electromyogr Kinesiol. 2013;23(2):285-295; doi: 10.1016/j. jelekin.2012.09.008.

28. Mehta RK. Impacts of obesity and stress on neuromuscular fatigue development and associated heart rate variability. Int J Obes. 2015;39(2):208-213; doi: 10.1038/ ijo.2014.127.

29. Mehta RK, Cavuoto LA. Relationship between BMI and fatigability is task dependent. Hum Factors. 2017;59(5): 722-733; doi: 10.1177/0018720817695194.

30. Guzmán-Muñoz E, Valdés-Badilla P, Concha-Cisternas Y, Méndez-Rebolledo G, Sazo-Rodríguez S. Influence of nutritional status on postural balance in children: a pilot study [in Spanish]. Rev Esp Nutr Hum Diet. 2017;21(1):49-54; doi: 10.14306/renhyd.21.1.297.

31. Wu H, Ballantyne CM. Skeletal muscle inflammation and insulin resistance in obesity. J Clin Invest. 2017; 127(1):43-54; doi: 10.1172/JCI88880.

32. Pellegrinelli V, Rouault C, Rodriguez-Cuenca S, Albert V, Edom-Vovard F, Vidal-Puig A, et al. Human adipocytes induce inflammation and atrophy in muscle cells during obesity. Diabetes. 2015;64(9):3121-3134; doi: 10.2337/db14-0796.

33. Phadke V, Ludewig PM. Study of the scapular muscle latency and deactivation time in people with and without shoulder impingement. J Electromyogr Kinesiol. 2013;23(2):469-475; doi: 10.1016/j.jelekin.2012.10.004. 